\title{
'Warehouse' or research centre? Analyzing public preferences for conservation, pre-breeding and characterization activities at the Czech genebank
}

\author{
Nicholas Tyack ${ }^{1,2}$ (D) $\cdot$ Milan Ščasný ${ }^{2,3,4}$ \\ Received: 8 February 2020 / Accepted: 23 April 2020 / Published online: 24 May 2020 \\ (C) International Society for Plant Pathology and Springer Nature B.V. 2020
}

\begin{abstract}
Genebanks are places where crop varieties are stored, catalogued, and made available for redistribution so that their genetic diversity is not lost. Besides conserving cultivated crop diversity, some genebanks also conserve the wild relatives of crops, which can contain useful traits not present in the domesticated genepool, and can undertake other activities to make genetic diversity more usable in breeding, such as characterization and evaluation efforts and pre-breeding. We present here the results of a stated preference survey that elicits the preferences of the general Czech public for the conservation of additional wheat and wild wheat varieties, characterization and evaluation activities, and pre-breeding efforts. Czech citizens were asked whether they would be willing to make a one-time voluntary payment to finance specific, 10-year conservation programmes at the Czech genebank. Using a sequence of single-bounded dichotomous choice questions, we estimate a random effects probit model to analyze preferences for such conservation programmes. We find that Czech respondents had a strong preference for characterization and evaluation, and while they do not value pre-breeding, they are willing to pay for the conservation of additional wild wheat accessions (though not for cultivated wheat varieties). In aggregate, the estimated benefits are substantial compared to the current costs of conservation. The stated preference approach of this paper permits the estimation of the social value of crop diversity conservation and associated investments in research, including non-market values. Our results provide information of potential use for policymakers in relation to setting priorities for the funding of agricultural research.
\end{abstract}

Keywords Genetic resources $\cdot$ Genebanks $\cdot$ Public goods $\cdot$ Stated preference $\cdot$ Willingness-to-pay $\cdot$ Crop wild relatives

\section{Introduction}

Genebanks are facilities designed to conserve and maintain genetic resources for the long term. The modern genebank system is partly a result of the observations of Nikolai Ivanovich Vavilov and Jack Harlan in the 1920s and 1930s, who noticed that traditional crop varieties or landraces were

Nicholas Tyack

nicholas.tyack@graduateinstitute.ch

1 Graduate Institute of International and Development Studies, Geneva, Switzerland

2 Faculty of Social Sciences, Institute of Economic Studies, Charles University, Prague, Czech Republic

3 Charles University Environment Centre, Prague, Czech Republic

4 Faculty of Finance and Accounting, University of Economics, Prague, Czech Republic disappearing from farmers' fields. Their observations lead to collection efforts for ex situ conservation of these materials in genebanks (Scarascia-Mugnozza and Perrino 2002). In the second half of the twentieth century, a global network of genebanks was established as part of the CGIAR, in part to address the observation that agricultural modernization and the spread of modern varieties were in the process of replacing the enormous diversity of traditional varieties cultivated in developing countries (Curry 2017). Today, crop diversity is conserved in a global system of national and international genebanks, with much of the diversity shared internationally through the Multilateral System of the International Treaty on Plant Genetic Resources for Food and Agriculture.

However, whereas genebanks were originally conceived as primarily storage facilities for genetic diversity to prevent its loss, scientists have more recently advocated for the transformation of genebanks into 'vibrant research centres' that work more actively to characterize and provide information on their holdings and collaborate to a greater extent with larger 
research and breeding communities (McCouch et al. 2012). Recent advances in biological science and information technologies have great potential to help improve the management and use of genetic diversity held within genebanks (Halewood et al. 2018). In addition, plant breeders have highlighted the importance of the wild relatives of crops, or crop wild relatives (CWR), which can contain useful traits not available in cultivated crop diversity, such as disease or pest resistance (Tanksley and McCouch 1997).

Scientists have argued that it is essential for twenty-first century genebanks to provide more information to potential users regarding the presence of useful genetic variation in different accessions and to facilitate the use of genebank holdings in breeding programmes (Mascher et al. 2019). Genebanks are seen as potential key nodes in an international system that contribute to global food security. Investments in agricultural research and development, such as the use of genetic resources in plant breeding, has proven to have a high rate of return. For example, Marasas et al. (2003) found that efforts to breed wheat cultivars resistant to leaf rust at the International Maize and Wheat Improvement Center (CIMMYT) had an internal rate of return of $41 \%$, while Brennan and Malabayabas (2011) estimated that an investment in rice improvement efforts at the International Rice Research Institute (IRRI) of about USD \$4.8 billion (2009 values) produced just over USD $\$ 100$ billion in benefits. ${ }^{1}$ More directly related to genebanks, Evenson and Gollin (1997) connected the addition of rice landraces into IRRI collections with the release of new varieties and improved productivity in farmers' fields, and concluded that the value of a single (non-redundant) rice landrace added to the genebank may have been worth as much as USD $\$ 50$ million. However, since genetic resources possess substantial non-market values, such as option or bequest value, it is also important to use other valuation methods, such as stated preference techniques, that allow the estimation of values not directly connected to the demonstrated use of genetic resources.

In this study, we use stated preference methods to investigate the extent to which the general Czech public is willing to support a shift to a more active genebank model characterized by more substantive investments into agricultural research. We report the results of an online experiment that investigated the willingness-to-pay (WTP) of a representative sample of individuals from the Czech Republic $(n=1037)$ for the conservation of additional cultivated varieties (a core genebank duty) as well as three additional attributes: 1) the conservation of wild relatives, 2) the undertaking of pre-breeding activities to make wild material more usable for breeders, and 3) characterization and evaluation activities to provide better information about the genebank's holdings. Surveying a sample

\footnotetext{
${ }^{1}$ IRRI and CIMMYT maintain two of the most important genebanks globally, for rice and maize/wheat, respectively.
}

representative of the Czech Republic as a whole allows the approximation of aggregate demand within the country (summing across the sampled population) for specific genebank activities. In addition, we also include a sub-sample of respondents from South Moravia $(n=500)$, an agricultural region of the Czech Republic, to investigate whether heterogeneity in preferences exists between more agricultural regions and the country as a whole. We focus our study on wheat, the most important crop in the Czech Republic by area planted and gross production value and a crop for which large genetic yield gaps have been found in the European context (Senapati and Semenov 2020).

A number of studies have used stated preference techniques to help capture the broader economic value of crop diversity conservation. For example, Poudel and Johnsen (2009) analyzed the WTP of Nepalese farmers for the conservation of rice landraces using an open-ended bidding game, while Rocchi et al. (2016) employed the single-bounded dichotomous choice method to estimate consumer use and nonuse values for an Italian tomato variety, 'Pomodoro di Mercatello'. More recently, Meier and Oehen (2019) used the price sensitivity meter or van Westendorp contingent valuation method to elicit whether consumers in Switzerland, France, Italy, and Spain were willing to pay a premium for farmers' tomato varieties in the supermarket. Others researchers have used the discrete choice experiment method, such as Sardaro et al. (2016) for olive landraces, Birol et al. (2006) in the context of Hungarian home gardens, and Tienhaara et al. (2019) for genetic resources in agriculture.

Some work has also been carried out to value crop wild relative genetic resources, such as Prescott-Allen and PrescottAllen (1986) and Pimentel et al. (1997). However, most of these analyses attempted to estimate the contributions provided by wild genetic material to current agricultural production (see Tyack and Dempewolf (2015) for a review). One exception is the study described by Hein and Gatzweiler (2006), where wild Coffea Arabica genetic resources in Ethiopian highland forests were valued by carrying out a net present value analysis of a hypothetical breeding programme for enhanced coffee cultivars with increased pest and disease resistance, low caffeine contents, and increased yields.

In contrast with most of the relevant previous work, this study focused on how the public values genebank activities besides conservation that provide benefits through their link to the breeding process and correspondent increases in agricultural productivity. We focused on whether the Czech public are willing to pay for programmes at the country's national genebank to conserve additional wheat and wild wheat varieties as well as to carry out pre-breeding or characterization and evaluation activities. We find that Czechs are willing to pay to support both characterization and evaluation activities as well as the conservation of wild wheat varieties, with an aggregate national willingness to pay of USD \$1.2 million per year for 
characterization and evaluation activities, and USD $\$ 650,000$ annually for a program conserving ten additional wild wheat varieties. In addition, we find an aggregate WTP across the region of South Moravia of USD \$160,000 annually to support pre-breeding activities, demonstrating that preferences are not homogenous across the country. Our results show that Czech citizens at least state that they are willing to support further investment in public agricultural research, conservation activities to increase the number of conserved wild species, and characterization and evaluation efforts to provide better information about the national genebank holdings, though their WTP for non-core genebank activities is lower than that previously estimated for the conservation of crop diversity in general (Tyack and Ščasný 2018).

Section two of this paper presents a brief review of related literature. Section three describes our methodology, including the experiment and survey instrument, data collection, and econometric approach. In section four, we present the main empirical results. Section five provides a discussion of the results and the policy implications of our findings, while section six presents our conclusions.

\section{Data and methods}

In this section we describe how the survey was designed and tested, the data collection process, and the econometric approach used in our analysis.

\subsection{Experiment and survey instrument}

Our experiment was designed to elicit the preferences of the Czech public for four genebank activities: 1) the conservation of cultivated wheat varieties, 2) the conservation of wild wheat varieties, 3) the undertaking of pre-breeding, and 4) characterization and evaluation activities. We did this by providing the individuals surveyed with a choice between the status quo and a 10-year conservation programme characterized by different values of the four attributes plus cost (a description of each attribute is provided in Table 1). We used a D-efficient design with 75 choice tasks grouped in 15 blocks, giving five tasks to each respondent.

Figure 1 provides an example of the binary-choice cards provided in our online survey. Each respondent was asked to choose between a conservation programme and the status quo five times, with each proposed conservation plan representing different combinations of the attribute levels.

The survey instrument used as part of our experiment was drafted in English, translated into Czech, and then programmed into an online format following a qualitative presurvey by the Charles University Environment Center. An online survey instrument was used to enable the use of more flexible experimental designs and randomizations. The experiment was preceded by three other related choice experiments (with relevant explanatory text) as well as questions to confirm the survey quota filling and screening questions, questions about the respondent's values and attitudes towards crop diversity, and introductory text about crop diversity and its importance. Socio-demographic information and other attitudinal questions were placed at the end of the survey instrument. The survey was further tested through a three-day online pilot of 175 members of the Czech public.

\subsection{Data collection}

The main wave of data collection was implemented over a fiveday period by a professional survey and public opinion company (STEM/MARK) that was responsible for quota management, incentivizing respondents to answer the survey, and to ensure that data collection was carried out according to the standards of the international research association, European Society for Opinion and Marketing Research (ESOMAR). Respondents were sampled from an internet panel managed by the Český Národní Panel (https://www.narodnipanel.cz/). The representativeness of both the national and South Moravian samples were ensured through quota selection dependent on
Table 1 Description of programme attributes and their levels

\begin{tabular}{|c|c|c|}
\hline $\begin{array}{l}\text { Programme } \\
\text { attribute }\end{array}$ & Attribute levels & Explanation \\
\hline Wheat varieties & $0,5,10,20,25,40$ & $\mathrm{X}$ wheat varieties conserved for the next 10 years \\
\hline $\begin{array}{l}\text { Wild wheat } \\
\text { varieties }\end{array}$ & $0,5,10,20,25,40$ & $\mathrm{X}$ wild wheat varieties conserved for the next 10 years \\
\hline Pre-breeding & Yes, No & $\begin{array}{l}\text { Pre-breeding activities carried out over the next } 10 \text { years to render } \\
\text { wild wheat holdings more usable by breeders }\end{array}$ \\
\hline $\begin{array}{l}\text { Characterization } \\
\text { and evaluation }\end{array}$ & Yes, No & $\begin{array}{l}\text { Characterization and evaluation activities carried out over the next } \\
10 \text { years to provide more information to breeders regarding the } \\
\text { genebank's holdings }\end{array}$ \\
\hline Cost & $\begin{array}{l}50,100,200,300 \\
500,600 \mathrm{CZK}\end{array}$ & One-time voluntary payment to into a public fund \\
\hline
\end{tabular}




\begin{tabular}{|l|}
\hline \\
\hline Conserve more wheat varieties \\
\hline Conserve more wild wheat varieties \\
\hline Characterization and evaluation \\
\hline Pre-breeding \\
\hline Your one-time payment \\
\hline
\end{tabular}

\section{Which do you prefer?}

Fig. 1 Example of a binary-choice experiment

education, age, gender, region, and the size of the place of residence of the respondent (see Table 9 in the Appendix 1). Both samples were not found to be statistically different at the $5 \%$ level from the set quotas for the targeted variables.

We further controlled for respondents who answered questions too quickly without carefully reading them by excluding surveys in which the survey respondent took less than $48 \%$ of the median time in the sub-sample (see Table 8 in Appendix 1). This left a total of 965 valid observations for the Czech representative sample and 463 for the South Moravian sample. The share of 'speeders' is 6.9 and $7.4 \%$, respectively. Descriptive statistics for variables of interest are provided in Table 2.

About $63 \%$ of respondents in the Czech representative sample had a garden, either at their primary residence, cottage,

\begin{tabular}{|c|c|}
\hline Programme X & Status quo \\
\hline 30 more varieties & None \\
\hline 10 more varieties & None \\
\hline No \\
\hline Yes \\
\hline $300 \mathrm{Kc \check {c }}$ \\
\hline \\
\hline \\
\hline
\end{tabular}

or community garden. The share of gardeners was only slightly greater $(68 \%)$ in the more agricultural region of South Moravia. In both samples, slightly more than half of survey participants thought that adaptation to climatic change in the Czech agriculture sector is important. Only about half as many (6\%) of the South Moravian respondents visited farmers' markets, as in the Czech representative sample, while about $60 \%$ of respondents in each sample had heard of genebanks.

\subsection{The econometric approach}

We assumed that the responses to the dichotomous choice questions were driven by a random utility model (Train 2003), where the deterministic part of the indirect utility
Table 2 Descriptive statistics for the survey sample (excluding speeders)

\begin{tabular}{lll}
\hline Model & General population $(n=965)$ & South Moravia $(n=463)$ \\
\hline Respondent's after-tax monthly income & $\$ 584.98$ & $\$ 632.90$ \\
Income information not provided & $3.3 \%$ & $5.4 \%$ \\
Age (continuous) & 43.35 & 43.37 \\
Male & $48.5 \%$ & $45.6 \%$ \\
Higher education & $14.1 \%$ & $15.6 \%$ \\
Student & $8.1 \%$ & $5.2 \%$ \\
Unemployed & $3.9 \%$ & $4.3 \%$ \\
City & $23.8 \%$ & $31.1 \%$ \\
South Moravia & $10.6 \%$ & $100.0 \%$ \\
Gardener & $63.1 \%$ & $68.3 \%$ \\
Agriculture adaptation important & $53.9 \%$ & $54.6 \%$ \\
Employment in agriculture sector & $1.7 \%$ & $2.4 \%$ \\
Visits farmers' market & $13.7 \%$ & $6.3 \%$ \\
Heard of genebank & $58.8 \%$ & $61.6 \%$ \\
\hline
\end{tabular}

Note: Monetary values are expressed in USD, using the exchange rate from 23 July 2016 of 24.62 CZK per USD, retrieved from https://www.xe.com immediately after the period of the study 
depends on the attributes of the given conservation programme:

$$
\begin{aligned}
\mathrm{V}_{i j t}= & \alpha_{1} W_{H E A T} T_{i j t}+\alpha_{2} W_{I L D_{i j t}}+\alpha_{3} \text { BREED }_{i j t} \\
& +\alpha_{4} E V A L U_{i j t}+\beta \cdot\left(y_{i}-B I D_{i j t}\right),
\end{aligned}
$$

where subscript $i$ denotes the individual, $j$ describes a programme $(=1)$ or the option without a programme $(=0)$, and $t$ is choice task $(1, \ldots, 5)$. These parameters describe programme attributes: the conservation of cultivated (WHEAT) and wild wheat varieties (WILD), respectively, undertaking of prebreeding (BREED), characterization and evaluation activities (EVAL), and the programme cost (BID). The $\alpha$ 's represent marginal utilities, while $\beta$ is the marginal utility of income.

The responses to the dichotomous choice questions were driven by the WTP for the conservation programme. Since we used a (sequence of) single-bounded dichotomous choice questions, the WTP was not directly observed and we assumed it depends on the magnitude of programme's attributes as follows:

$W T P_{i j t}^{*}=\alpha_{0}+\boldsymbol{X}_{i j t} \boldsymbol{\alpha}+\varepsilon_{i j t}$,

where $\mathrm{X}$ is a vector of programme's attributes (WHEAT, WILD, BREED, EVAL) and the stochastic term $\varepsilon$ is assumed to be normally distributed with mean zero and variance $\sigma^{2}$.

We did not observe the true WTP for a specified programme. We know, however, if the respondent chooses a programme $(j=1)$, their underlying WTP is greater than the cost, i.e. the bid of the programme. This implies that the probability of choosing a programme is a function of the magnitude of the programme's attributes, including its cost:

$\operatorname{Pr}(j)=\operatorname{Pr}\left(W T P_{i j t}^{*} \geq B I D_{i j t}\right)=\Phi\left(a_{0}+\boldsymbol{X}_{i j t} \boldsymbol{a}+b \cdot B I D_{i j t}\right)$,

where $\Phi(\cdot)$ denotes the standard normal cdf, $a_{0}=\alpha_{0} / \sigma, \boldsymbol{a}=\boldsymbol{\alpha} /$ $\sigma, b=-1 / \sigma$, and appropriate statistical model is a probit.

Since we used a sequence of five binary-choice questions for each respondent, our observations were not independent and the five responses and a five corresponding error terms were likely correlated. We assumed that the correlation between any two pairs of responses was the same, implying a two-level random effects probit statistical model, as introduced by Laird and Ware (1982) and developed for binary response data by Gilmour et al. (1985). If the estimate of the rho coefficient is very close to zero, then the extent of intrapanel correlation is small enough and it would be acceptable to use a one-level model such as probit or logit on panel data. The coefficient rho $=\operatorname{Corr}\left[\varepsilon_{i j}, \varepsilon_{i s}\right]=\sigma_{u}^{2} /\left(1+\sigma_{u}^{2}\right)$, where $\varepsilon_{i t}=\left(v_{i j}+u_{i}\right), \operatorname{Var}\left[\varepsilon_{i t}\right]=\sigma_{v}^{2}+\sigma_{u}^{2}=1+\sigma_{u}^{2}$, and $\sigma_{u}^{2}$ is the panel-level variance - the individual-specific portion of the error term (see Greene (2007)). We use the xtprobit STATA 15 command to estimate our models.

The WTP values were estimated by dividing the random effects coefficients for each given programme attribute (or respondent characteristic) by the cost variable multiplied by negative one (Cameron and James 1987). We computed the standard errors around the mean WTP estimates using the delta method, with nlcom in STATA.

\section{Results}

In this section, we present the two main results of our analysis: first, our WTP estimates for the four non-monetary programme attributes for the Czech general population and the South Moravian sub-samples, and second, the results from a random effects probit model for both samples controlling for socio-economic variables. Estimates of the aggregate WTP for national programmes are reported in the next section.

In Table 3, we present the results for our basic random probit analysis for the Czech general population sample,
Table 3 Random effects probit regression results for the Czech sample, basic model

\begin{tabular}{lll}
\hline Variable & Czech sample (no speeders) & Czech sample (with speeders) \\
\hline Wheat & $-0.001(0.002)$ & $-0.001(0.002)$ \\
Wild Wheat & $0.009 * * *(0.002)$ & $0.009 * * *(0.002)$ \\
Pre-breeding & $0.004(0.068)$ & $0.010(0.065)$ \\
Characterization and evaluation & $0.164 * *(0.060)$ & $0.138^{* *}(0.057)$ \\
Cost (in CZK) & $-0.004 * * *(0.000)$ & $-0.004 * * *(0.000)$ \\
Constant & $-0.177 *(0.105)$ & $-0.175 *(0.100)$ \\
& No. of respondents: 965 & No. of obs: 1037 \\
& No. of obs.: 4825 & No. of obs.: 5185 \\
& Log-likelihood: -2134.137 & Log-likelihood: -2321.080 \\
& Rho $=0.807$ & Rho $=0.805$ \\
\hline
\end{tabular}

Note: $* * *$, and $* * *$ represent 10,5 , and $1 \%$ significance levels, respectively; standard errors in parentheses 
including the results of regressions that include and exclude speeders. We found that Czechs in general are only WTP for the conservation of additional wild wheat varieties and for conservation plans that include a characterization and evaluation component (not for cultivated wheat varieties or for prebreeding activities). We estimated that Czechs are WTP about USD $\$ 1.67$ on average per respondent for a 10 -year conservation plan that includes characterization and evaluation activities, and about USD $\$ 0.09$ per wild wheat accession conserved by the programme. The WTP values were converted to USD using the exchange rate at the time of the survey (1 $\mathrm{USD}=24.62 \mathrm{CZK}$ ).

In Table 4, we present the results for our basic random probit analysis for the South Moravian sub-sample, including the results of regressions that both include speeders and exclude them.

We found that residents of South Moravia similarly value the conservation of wild wheat varieties (and not the conservation of cultivated wheat varieties). However, in contrast with the Czech representative sample, they are willing to pay for prebreeding activities (for the sample with speeders excluded) but not for characterization and evaluation activities.

Table 5 presents the mean WTP figures for each programme attribute by sample in US dollars, estimated using the delta method. We take the estimates for the samples with speeders excluded as our preferred WTP estimates, to control for respondents who took $47 \%$ or less of the median time (and may have rushed through the survey). We found that both Czech and South Moravian respondents were willing to pay about the same amount for the conservation of wild wheat relatives, with a WTP of USD $\$ 0.09$ per variety in the Czech sample and a WTP of USD $\$ 0.11$ per variety in the South Moravian sample. In contrast, the only other attribute that the Czech representative sample is willing to pay for is characterization and evaluation (with a mean WTP of about USD \$1.67), while respondents from South Moravia are not willing to pay anything. The opposite is true for pre-breeding activities: while Czechs are not willing to pay anything, respondents from South Moravia are, on average, willing to pay USD \$1.94 (with a standard error of USD \$1.04).

We present the results of probit regressions for both the Czech and South Moravian samples, including socioeconomic variables, in Table 6 . We found some significant socio-economic and attitudinal drivers of respondents' WTP for conservation programmes. For example, for the Czech representative sample, WTP was found to increase with personal after-tax monthly income and to decrease with age, with respondents between 18 and 30 willing to pay the most for a conservation programme. Other significant variables include whether the respondents had heard of a genebank before or whether they believed it to be important to make investments in Czech agriculture to adapt to climate change.

WTP in the South Moravian sample was found to be unaffected by income or age, and WTP was more sensitive, than in the Czech sample, to whether respondents had heard of genebanks or believed it to be important that the Czech Republic invest in agriculture for climate change adaptation. In addition, we found that gardeners in South Moravian were willing to pay more for a conservation programme.

\section{Discussion}

Our results show that Czech citizens value the conservation of additional varieties of wild wheat but not the conservation of additional varieties of cultivated wheat. Preferences for the conservation of wild wheat varieties is most likely driven by the belief of respondents that wild species may contain more genetic diversity than cultivated wheat, including genetic traits, such as heat and drought tolerance, that are useful for climate change adaptation. In fact, survey participants who stated that they believe that adaptation to climate change in the agriculture sector is important were also more likely to
Table 4 Random effects probit regression results for South Moravia, basic model

\begin{tabular}{lll}
\hline Variable & South Moravia (no speeders) & South Moravia (with speeders) \\
\hline Wheat & $-0.006(0.004)$ & $-0.006(0.004)$ \\
Wild wheat & $0.011^{* *}(0.005)$ & $0.010^{* *}(0.004)$ \\
Pre-breeding & $0.188^{*}(0.101)$ & $0.135(0.096)$ \\
Characterization and evaluation & $0.089(0.090)$ & $0.076(0.085)$ \\
Cost (in CZK) & $-0.004^{* * *(0.000)}$ & $-0.004 * * *(0.000)$ \\
Constant & $-0.213(0.162)$ & $-0.116(0.154)$ \\
& No. of respondents: 463 & No. of respondents: 500 \\
& No. of obs.: 2315 & No. of obs.: 2500 \\
& Log-likelihood: -987.601 & Log-likelihood: -1086.505 \\
& Rho $=0.835$ & Rho $=0.831$ \\
\hline
\end{tabular}

Note: $* * *$, and $* * *$ represent 10,5 and $1 \%$ significance levels, respectively; standard errors in parentheses 
Table 5 Estimated mean WTP figures for each programme attribute and by sample

\begin{tabular}{lll}
\hline Programme attribute & Estimated WTP (Czech sample) & Estimated WTP (S. Moravian sample) \\
\hline Wheat varieties & $\$ 0$ & $\$ 0$ \\
Wild wheat varieties & $\$ 0.09(\$ 0.02)$ & $\$ 0.11(\$ 0.05)$ \\
Pre-breeding & $\$ 0$ & $\$ 1.94(\$ 1.04)$ \\
Characterization and evaluation & $\$ 1.67(\$ 0.61)$ & $\$ 0$ \\
\hline
\end{tabular}

Note: standard errors in parentheses. All currency values are in USD; WTP figures are for activities carried out over a 10 -year period contribute to a proposed programme. Czech respondents were also willing to pay for characterization and evaluation in order to measure different characteristics of crop varieties related to agronomic performance, such as yield and resistance to drought and pests. They were not, however, in favour of paying for pre-breeding.

In Table 7, we provide rough estimates of the aggregate country-wide marginal benefits for specific conservation plans obtained by multiplying the mean WTP estimates by the population (around 7.5 million and 800,000 for Czech and South Moravia, respectively) for the sampled age range of 18-69.

We found that Czechs in aggregate were willing to pay USD $\$ 650,000$ for the conservation of a single variety of wild wheat over a ten-year period, ${ }^{2}$ USD \$13 million for the conservation of 20 wild wheat varieties (the average for our design), and USD \$26 million for 40 wild wheat varieties (the maximum offered in our design). In addition, we find that the Czech public as a whole is also willing to pay $\$ 12.5$ million to fund a ten-year characterization and evaluation program at the national genebank. And while Czechs in general were not willing to pay to fund prebreeding activities, we find that respondents in the region of South Moravia had an aggregate WTP of \$1.6 million for a ten-year prebreeding program, illustrating preference heterogeneity between regions of the Czech Republic. The mean WTP for characterization and evaluation for the general sample was close to that for pre-breeding stated by South Moravia respondents, the difference in the aggregate estimates is due to the different sizes of these populations. These countrywide estimates are substantial when compared to the 10-year costs of running the entire Czech genebank system (including the conservation of livestock and microbes) of USD \$14.6 million (based on 2017 costs; cost estimates were provided by Dr. Vojtech Holubec of the Czech Crop Research Institute).

About $40 \%$ of respondents had not heard about genebanks before participating in the survey. In order to help respondents make well-informed decisions, we provided factual, neutral, information about the attributes of the offered programme (see Appendices 2 and 3), acknowledging that such basic, factual, information may potentially affect the decision-making of survey participants. We consider this source of potential bias

\footnotetext{
${ }^{2}$ The WTP figures are in each case for the funding of a conservation program over a ten-year period.
}

acceptable, since a questionnaire survey will likely include 'a balanced and effective presentation of information' (Johnston et al. 2017)), and following the practice of recent stated preference work investigating the valuation of genetic resource conservation (Tienhaara et al. 2019). Similar to the results found by Tyack and Ščasný (2018), we found that respondents who had heard about a genebank beforehand were more likely to contribute to a conservation fund. These two samples are not however the same in terms of their demographic characteristics: respondents who heard about a genebank were found more likely to be males, to be more highly educated, older than 30 years old, city dwellers, gardeners, and to think that investments in adaptation in the agriculture sector are important (see Tyack and Ščasný 2018). When we ran the samples separately using two separate probit models, we found that the aggregate and marginal WTP estimates were not statistically different (these results are available on request).

While answering the five binary-choice questions, we asked respondents to forget their previous answers and imagine a scenario where they had made no payments or commitments to fund a conservation programme of any kind. This strategy implied that each of the five choice questions should be considered independently, against no action, regardless of their responses to the previous choice questions in our valuation experiment. However, because survey participants were asked to evaluate all five tasks in the same survey and the same survey section, we structure the data as a panel and adopted a randomeffects probit model, as required by econometrics practice (Greene 2007). Indeed, the estimated variance on the individual-specific error term was significantly different from zero and the implied rho coefficient was about 0.80 , suggesting that a random-effects probit estimation is an appropriate model for our data.

\section{Conclusion}

The strength and contribution of this study is its application of stated preference methods to the public valuation of the conservation of crop wild relatives, of activities to better characterize and evaluate holdings of crop diversity, and of investments in agricultural research and development (pre-breeding). Even within the relatively limited 
Table 6 Random probit results for the Czech and South Moravian samples with socioeconomic variables

\begin{tabular}{|c|c|c|}
\hline Variable & Czech sample (no speeders) & South Moravia (no speeders) \\
\hline Wheat & $0.001(0.002)$ & $-0.006(0.004)$ \\
\hline Wild wheat & $0.009 * * *(0.002)$ & $0.011 * *(0.005)$ \\
\hline Pre-breeding & $0.003(0.068)$ & $0.182 *(0.101)$ \\
\hline Characterization \& evaluation & $0.162 * * *(0.060)$ & $0.090(0.090)$ \\
\hline Cost & $-0.004 * * *(0.000)$ & $-0.004 * * *(0.000)$ \\
\hline Personal income & $0.211 * *(0.093)$ & $0.090(0.112)$ \\
\hline Personal income missing & $-0.061(0.445)$ & $-0.197(0.536)$ \\
\hline Student & $-0.306(0.320)$ & $0.574(0.566)$ \\
\hline Unemployed & $-0.032(0.388)$ & $0.235(0.550)$ \\
\hline City & $-0.090(0.178)$ & $0.411(0.250)$ \\
\hline Age $30-60$ & $-0.400 * *(0.194)$ & $0.023(0.298)$ \\
\hline Age, $60 \mathrm{~s}$ & $-0.674 * * *(0.234)$ & $-0.275(0.372)$ \\
\hline Gardener & $0.177(0.156)$ & $0.758 * * *(0.253)$ \\
\hline Agr. adaptation important & $0.775 * * *(0.152)$ & $1.064 * * *(0.234)$ \\
\hline Employed in agriculture & $0.740(0.560)$ & $-0.122(0.761)$ \\
\hline Visits farmers' markets & $0.180(0.213)$ & $0.055(0.468)$ \\
\hline Heard of genebanks & $0.469 * * *(0.156)$ & $0.860 * * *(0.244)$ \\
\hline \multirow[t]{5}{*}{ Constant } & $-0.908 * * *(0.268)$ & $-2.101 * * *(0.420)$ \\
\hline & No. of respondents: 965 & No. of respondents: 463 \\
\hline & No. of obs: 4825 & No. of obs: 2315 \\
\hline & Log-likelihood: -2103.086 & Log-likelihood: -960.704 \\
\hline & Rho $=0.794$ & Rho $=0.812$ \\
\hline
\end{tabular}

Note: $* * *$, and $* * *$ represent 10,5 and $1 \%$ significance levels, respectively; standard errors in parentheses stated preference literature that focuses on the value of genetic resources and crop diversity, these three areas have not been explored adequately, and thus, this analysis represents an effort to broaden investigations of the value provided by genebank operations beyond just the conservation of cultivated crop diversity.

We found that the Czech public as a whole is willing to support substantial investments in characterization and evaluation activities as well as further conservation of wheat wild relatives, and to a lesser extent, a small investment in prebreeding (though only South Moravian respondents were

Table 7 Aggregate marginal WTP figures for programme attributes in the Czech Republic

\begin{tabular}{ll}
\hline Model & Estimated aggregate WTP \\
\hline One variety of wild wheat conserved & $\$ 650,000$ \\
10 varieties of wild wheat conserved & $\$ 6.5$ million \\
20 varieties of wild wheat conserved & $\$ 13$ million \\
40 varieties of wild wheat conserved & $\$ 26$ million \\
Characterization and evaluation activities & $\$ 12.5$ million \\
Pre-breeding activities (only S. Moravia) & $\$ 1.6$ million \\
\hline
\end{tabular}

Note: all currency values are in USD; WTP figures are for activities carried out over a 10 -year period willing to financially support pre-breeding activities, not Czech citizens in general). These empirical results are interesting because they show that Czech citizens would likely support further investment in public agricultural research and conservation activities to increase the number of conserved wild species (or accessions) and to provide better information about the national genebank holdings, though their WTP for non-core genebank activities is lower than that previously estimated for the conservation of crop diversity in general (Tyack and Ščasný 2018). Outside of the Czech Republic, this research is also of interest on an international level given the global public good characteristics of crop diversity and information and research associated with genetic resources. For example, the Czech genebank's collection of 21 species of wild wheat relatives hailing from a broad geographical range across the territory of the former Soviet Union to Portugal includes many Aegilops species with resistance to powdery mildew and other crop diseases such as leaf and stem rusts. These holdings act as a global public good given that these accessions are publicly available through the Multilateral System (Holubec et al. 1992). Thus, the Czech genebank distributes the crop diversity it maintains internationally, and the improved information and usability of the Czech crop collections provided through genetic resource information systems has potential value for other countries as well. 
Acknowledgments The financial support provided by the Charles University Grant Agency no. 796216 (NT) as well as the Czech Science Foundation grant number 19-26812X (MS) and by Charles University's PRIMUS/17/HUM/16 (NT). We would also like to thank those who helped with testing the survey instrument and with translation into the Czech language, and Vojtech Holubec and Ludmila Papoušková from the Crop Research Institute in Prague for their assistance with the research. Responsibility for any errors remains with the authors.
Authorship contribution Both authors contributed to the research conceptualization and design, data gathering, data analysis, writing, and editing.

\section{Compliance with ethical standards}

Conflict of interest The authors declare no conflict of interest.

\section{Appendix 1: Additional tables}

Table 8 Sub-samples and percentage of speeders

\begin{tabular}{lllll}
\hline Sub-sample & Mode & N (completed) & $\%$ speeders & N valid \\
\hline Czech Republic representative & CAWI & 1037 & $6.9 \%$ & 965 \\
S. Moravia representative & CAWI & 500 & $7.4 \%$ & 463 \\
\hline
\end{tabular}

Table 9 Quota variables with target and actual figures (and deviations)

\begin{tabular}{|c|c|c|c|c|c|}
\hline \multirow[t]{2}{*}{ Quota variable } & \multirow{2}{*}{$\begin{array}{l}\text { Quota Set } \\
\text { Proportion }\end{array}$} & \multicolumn{2}{|c|}{ Sample representative of Czech Republic $N=1037$} & \multicolumn{2}{|c|}{ Sample with excluded Speeders $N=965$} \\
\hline & & Proportion & Difference & Proportion & Difference \\
\hline \multicolumn{6}{|l|}{ Gender } \\
\hline male & $48.4 \%$ & $49.3 \%$ & $0.9 \%$ & $48.5 \%$ & $0.1 \%$ \\
\hline \multicolumn{6}{|l|}{ Education } \\
\hline Elementary \& secondary & $52.3 \%$ & $53.7 \%$ & $1.4 \%$ & $53.1 \%$ & $0.8 \%$ \\
\hline Secondary with A level & $32.7 \%$ & $32.2 \%$ & $-0.5 \%$ & $32.8 \%$ & $0.1 \%$ \\
\hline Tertiary & $15.0 \%$ & $14.1 \%$ & $-0.9 \%$ & $14.1 \%$ & $-0.9 \%$ \\
\hline \multicolumn{6}{|l|}{ Age } \\
\hline $18-34$ & $35.8 \%$ & $36.5 \%$ & $0.8 \%$ & $35.5 \%$ & $-0.2 \%$ \\
\hline $35-50$ & $29.8 \%$ & $27.5 \%$ & $-2.3 \%$ & $27.3 \%$ & $-2.5 \%$ \\
\hline $51-69$ & $34.4 \%$ & $36.0 \%$ & $1.5 \%$ & $37.2 \%$ & $2.8 \%$ \\
\hline \multicolumn{6}{|l|}{ Residence size } \\
\hline$<5000$ inhabitants & $40.9 \%$ & $41.7 \%$ & $0.7 \%$ & $42.0 \%$ & $1.0 \%$ \\
\hline 50,000 and more & $28.9 \%$ & $26.9 \%$ & $-2.0 \%$ & $26.8 \%$ & $-2.0 \%$ \\
\hline 50,000 inhabitants & $30.2 \%$ & $31.4 \%$ & $1.2 \%$ & $31.2 \%$ & $1.0 \%$ \\
\hline \multicolumn{6}{|l|}{ Regions } \\
\hline Capital city of Prague & $12.6 \%$ & $11.8 \%$ & $-0.8 \%$ & $11.6 \%$ & $-1.0 \%$ \\
\hline Central Bohemian & $12.2 \%$ & $12.3 \%$ & $0.1 \%$ & $12.4 \%$ & $0.2 \%$ \\
\hline South Bohemian + Pilsen & $11.5 \%$ & $12.0 \%$ & $0.5 \%$ & $12.2 \%$ & $0.7 \%$ \\
\hline Karlovy Vary + Usti n.L. & $10.4 \%$ & $10.0 \%$ & $-0.4 \%$ & $10.2 \%$ & $-0.2 \%$ \\
\hline Liberec + H.Kralove + Pardubice & $14.2 \%$ & $14.8 \%$ & $0.6 \%$ & $14.9 \%$ & $0.7 \%$ \\
\hline Olomouc + Zlin + Vysocina & $16.4 \%$ & $17.0 \%$ & $0.6 \%$ & $16.7 \%$ & $0.3 \%$ \\
\hline Moravskoslezský & $11.2 \%$ & $10.7 \%$ & $-0.5 \%$ & $10.6 \%$ & $-0.6 \%$ \\
\hline Jihomoravský & $11.5 \%$ & $11.5 \%$ & $0.0 \%$ & $11.4 \%$ & $-0.1 \%$ \\
\hline
\end{tabular}




\section{Appendix 2: Preferences for conservation of wheat and wild wheat, characterization and evaluation, and pre-breeding}

Genebanks are places where individual crop varieties are kept so that their genetic diversity is not lost. Individual varieties are catalogued and ready for further redistribution. In addition to the conservation of individual crop varieties, as described above, genebanks and related wild species to the crops, which can provide useful new features through pre-breeding, are maintained.

For example, the Crop Research Institute v.v.i. in PragueRuzyně conserves, along with cultivated wheat, a large number of wild wheat varieties.

Wild varieties generally provide a wider genetic diversity than bred wheat and provide properties such as increased resistance to heat and drought that are useful in adapting to climate change.

Have you ever heard of genebanks?

- Yes.

- No.

\section{******** NEW SCREEN ********}

The seed banks can also carry out two other sets of activities to increase the value of their holdings:

1. Characterization and evaluation: Seed banks can plant crop varieties and measure different characteristics related to agronomic performance, such as yield and resistance to drought and pests. This useful information helps plant breeders to more effectively use the contents of seed banks to create new, improved varieties.

2. Pre-breeding: Wild species are distantly related to modern crop varieties, so it takes extra time and effort to insert the trait of interest into a cultivated crop. Seed banks can carry out pre-breeding efforts to help introduce valuable traits from their holdings into more usable breeding lines.

Funding pre-breeding and characterization \& evaluation programs is a good way to improve the usefulness of the seed bank's collections and increase the chance that plant breeders, farmers and consumers will benefit from the genetic diversity contained at the seed bank.

******** NEW SCREEN ********.

This portion of the survey asks you to make choices between funding or not funding a 10-year program at the seed bank, based on the details of the program. These details include:

- the number of additional wheat and wild wheat varieties conserved;
- whether pre-breeding and/or characterization and evaluation efforts are supported;

- how much you would be required to pay.

If you choose to fund the program, you would provide your financial support in the form of a one-time, voluntary payment into a public fund to finance the specific program described in the question.

Wheat is the most important crop in the Czech Republic (in terms of gross production value), and the activities described here could protect $\mathrm{Czech}$ wheat agriculture against disease, pests or climate fluctuations and make it more productive.

Please consider carefully which options you would realistically pay for, given your current budget.

Also, while answering, please try to forget your previous answers and imagine a scenario where you have made no payments or commitments to fund the conservation of Czech crop diversity of any kind.

\section{Appendix 3: Introductory text on the value of crop diversity}

What is the meaning of crop diversity and why is it important? $?^{3}$

The concept of crop diversity can be easily explained by the fact that a given crop is not uniform but is made up of many different varieties that vary significantly and may have unique characteristics.

For example, the image below shows one bean variety (source: Global Crop Diversity Trust Flickr).

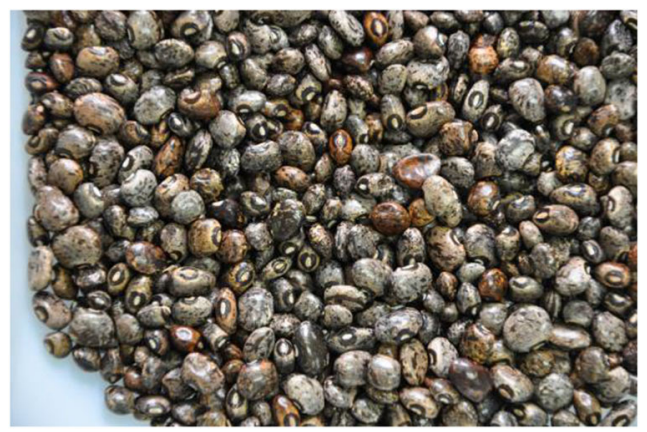

In contrast, the following picture shows many different varieties of beans.

\footnotetext{
${ }^{3}$ An English version of the text was provided to Czech survey respondents prior to the contingent valuation questions.
} 


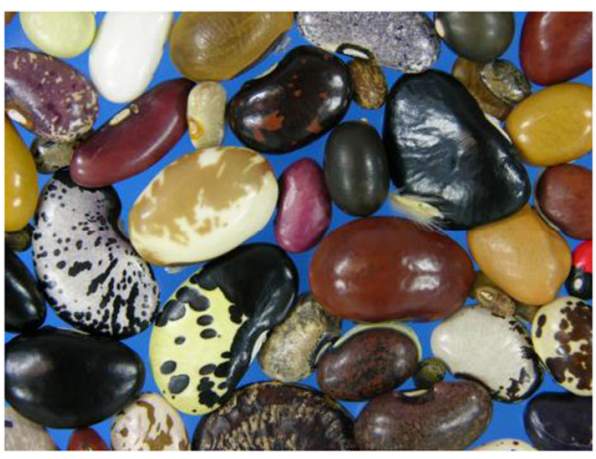

Crop diversity is of economic value and helps to ensure food security. It is of particular value for the following two reasons:

- Genetic diversity in different crop varieties is valuable for breeding new, improved varieties of crops that are more profitable and resilient.

- Crop varieties also provide benefits and value for farmers who grow them as well as those who then consume or otherwise use the resulting products.

Crop varieties are stored in 'genebanks', which are the places where the seeds, tubers, and samples of various crops are conserved and maintained.

In the Czech Republic, crop diversity is maintained by the public National Programme for the Conservation and Use of Genetic Resources of Plants Important to Nutrition and Agriculture.

\section{References}

Birol, E., Smale, M., \& Gyovai, A. (2006). Using a choice experiment to estimate farmer's valuation of agrobiodiversity on hungarian small farms. Environmental and Resource Economics, 34, 439-469.

Brennan, J. P., \& Malabayabas, A. (2011). International ice research Institute's contribution to rice varietal yield improvement in SouthEast Asia. ACIAR impact assessment series no. 74. Canberra: Australian Centre for International Agricultural Research.

Cameron, T. A., \& James, M. D. (1987). Efficient estimation methods for "closed-ended" contingent valuation surveys. The Review of Economics and Statistics, 69(2), 269-276.

Curry, H. A. (2017). From working collections to the world Germplasm project: Agricultural modernization and conservation at the Rockefeller Foundation. History and Philosophy of the Life Sciences, 39(2), 5.

Evenson, R. E., \& Gollin, D. (1997). Genetic resources, international organisations, and improvement in rice varieties. Economic Development and Cultural Change, 45(3), 471-500.

Gilmour, A. R., Anderson, R. D., \& Rae, A. L. (1985). The analysis of binomial data by generalized linear mixed model. Biometrika, 72, $593-599$.

Greene, W. H. (2007). Econometric analysis (Sixth ed.). Upper Saddle River: Prentice-Hall, Inc..

Halewood, M., Chiurugwi, T., Hamilton, R. S., Kurtz, B., Marden, E., Welch, E., et al. (2018). Plant genetic resources for food and agriculture: Opportunities and challenges emerging from the science and information technology revolution. New Phytologist, 217, $1407-1419$
Hein, L., \& Gatzweiler, H. (2006). The economic value of coffee (Coffea arabica) genetic resources. Ecological Economics, 60, 176-185.

Holubec, V., Hanusova, R., \& Kostkanova, E. (1992). The Aegilops collection in the Praha-Ruzyne (Czechoslovakia) Genebank: Collecting, evaluation and documentation. Hereditas, 116, 271-276.

Johnston, R. J., Boyle, K. J., Adamowicz, W., Bennett, J., Brouwer, R., Cameron, T. A., et al. (2017). Contemporary guidance for stated preference studies. Journal of Association of Environmental \& Resource Economics, 4, 319-405.

Laird, N. M., \& Ware, J. H. (1982). Random effects models for longitudinal data. Biometrics, 38, 963-974.

Marasas, C., Smale, M., \& Singh, R. (2003). The economic impact of productivity maintenance research: Breeding for leaf rust resistance in modern wheat. Agricultural Economics, 29, 253-263. https://doi. org/10.1111/j.1574-0862.2003.tb00162.x.

Mascher, M., Schreiber, M., Scholz, U., Graner, A., Reif, J. C., \& Stein, N. (2019). Genebank genomics bridges the gap between the conservation of crop diversity and plant breeding. Nature Genetics, 51, 1076-1081.

McCouch, S. R., McNally, K. L., Wang, W., \& Hamilton, R. S. (2012). Genomics of genebanks: A case study in rice. American Journal of Botany, 99(2), 407-423.

Meier, C., \& Oehen, B. (2019). Consumer's valuation of farmer's varieties for food system diversity. Sustainability, 11, 7134.

Pimentel, D., Wilson, C., McCullum, C., Huang, R., Dwen, P., Flack, J., Tran, Q., Saltman, T., \& Cliff, B. (1997). Economic and environmental benefits of biodiversity. BioScience, 47(11), 747-757. https://doi.org/10.2307/1313097.

Poudel, D., \& Johnsen, F. H. (2009). Valuation of crop genetic resources in Kaski, Nepal: Farmer's willingness to pay for rice landraces conservation. Journal of Environmental Management, 90, 483-491.

Prescott-Allen, C., \& Prescott-Allen, R. (1986). The first resource: Wild species in the north American economy (First ed.). New Haven: Yale University Press.

Rocchi, L., Paolotti, L., Cortina, C., \& Boggia, A. (2016). Conservation of landrace: The key role of the value for agrobiodiversity conservation. An application on ancient tomatoes varieties. Agriculture and Agricultural Science Procedia, 8, 307-316.

Sardaro, R., Girone, S., Acciani, C., Bozzo, F., Petrontino, A., \& Fucilli, V. (2016). Agro-biodiversity of Mediterranean crops: Farmer's preferences in support of a conservation program for olive landraces. Biological Conservation, 201, 210-219.

Scarascia-Mugnozza, G. T., \& Perrino, P. (2002). The history of ex situ conservation and use of plant genetic resources. In A. H. D. Brown \& M. Jackson (Eds.), Managing plant genetic resources (pp. 1-22). Oxfordshire: CABI Publishing.

Senapati, N., \& Semenov, M. A. (2020). Large genetic yield potential and genetic yield gap estimated for wheat in Europe. Global Food Security. https://doi.org/10.1016/j.gfs.2019.100340.

Tanksley, S. D., \& McCouch, S. R. (1997). Seed banks and molecular maps: Unlocking genetic potential from the wild. Science, 277(5329), 1063-1066.

Tienhaara, A., Ahtiainen, H., Pouta, E., \& Czajkowski, M. (2019). Role of information in the valuation of unfamiliar goods - The case of genetic resources in agriculture. Working paper no. 7/2019. Faculty of Economic Sciences, University of Warsaw, Warsaw, Poland.

Train, K. E. (2003). Discrete choice methods with simulation. Cambridge: Cambridge University Press.

Tyack, N., \& Dempewolf, H. (2015). The economics of crop wild relatives under climate change. In R. Redern, S. S. Yadav, N. Maxted, M. E. Dulloo, L. Guarino, \& P. Smith (Eds.), Crop wild relatives and climate change (pp. 281-291). Hoboken: Wiley-Blackwell.

Tyack, N., \& Ščasný, M. (2018). Social valuation of genebank activities: Assessing public demand for genetic resource conservation in the Czech Republic. Sustainability, 10(11), 3997. https://doi.org/10. 3390/su10113997. 


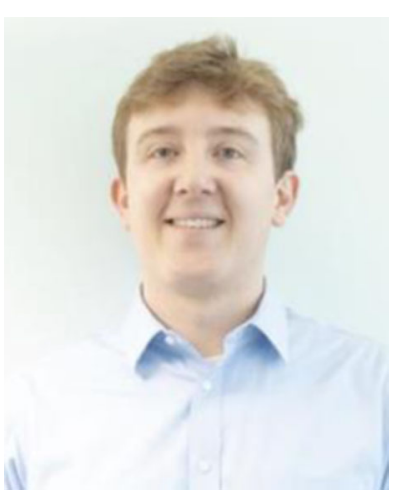

mental consultant in his home city of Boston.

Nicholas Tyack is a $\mathrm{PhD}$ candidate in Development Economics at the Graduate Institute of International and Development Studies in Geneva. He holds a master's degree in Economics from Charles University in Prague, and a bachelor's degree in Biology from Pomona College in Claremont, California. His research interests include the economic valuation of crop diversity and biodiversity, and he has worked with the Global Crop Diversity Trust and as an environ-

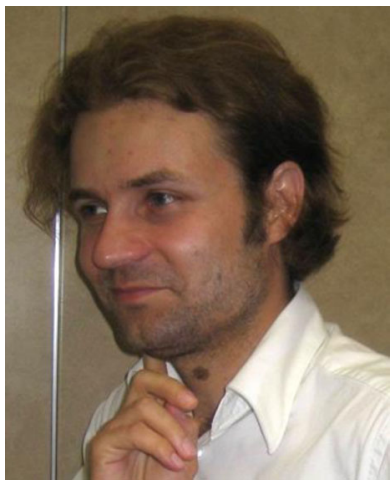

Milan Ščasný is a Senior Research Fellow at the Charles University Environment Center and the Institute of Economic Studies and also at the University of Economics in Prague, Czech Republic. His research activities cover environmental and behavioural economics, consumer demand, and the valuation of non-market goods, particularly for health risks, environmental and health external costs, and impact assessment. He has been involved in more than 30 research projects funded by the Framework Programmes of the European
Commission (CECILIE2050, COACCH, GEMCLIME, INHERIT), and recently has been coordinating the Horizon 2020 Marie SklodowskaCurie Action RISE project, 'Global Excellence in Modelling Climate and Energy Policies'. He has collaborated with the Organisation for Economic Co-operation and Development, the European Chemicals Agency, Health Canada, and many ministries and governmental bodies in the Czech Republic. He has published more than 40 articles in journals, which are included in the WoS Thomson Reuters database with a H-index 11 . 